\title{
Behavioural Responses of Crangon crangon (Crustacea, Decapoda) to Reduced Seawater pH Following Simulated Leakage from Sub-Sea Geological Storage
}

\author{
Gerhardt Almut $^{1,2}$, Shaw Bamber ${ }^{1}$ \\ ${ }^{1}$ International Research Institute of Stavanger (IRIS), Stavanger, Norway; ${ }^{2}$ LimCo International GmbH, Konstanz, Germany. \\ Email: almutg@web.de \\ Received May $24^{\text {th }}, 2013$; revised June $28^{\text {th }}, 2013$; accepted July $6^{\text {th }}, 2013$ \\ Copyright (C) 2013 Gerhardt Almut, Shaw Bamber. This is an open access article distributed under the Creative Commons Attribu- \\ tion License, which permits unrestricted use, distribution, and reproduction in any medium, provided the original work is properly \\ cited.
}

\begin{abstract}
Carbon capture and storage (CCS) in sub-sea geological formations is being developed and promoted to mitigate $\mathrm{CO}_{2}$ discharges to the atmosphere from point sources such as power stations. There remain some questions on the risks associated with the possible loss of gas from storage and the environmental harm this could pose to marine organisms associated with the sea bed in these regions. This study investigated the effect of exposing the common shrimp (Crangon crangon) to reduced $\mathrm{pH}$ conditions and presents the results of stepwise $\mathrm{pH}$-reductions $(0.2 \mathrm{pH}$ units from $\mathrm{pH} 7$ down to $\mathrm{pH}$ 6). Behaviour was monitored continuously throughout 8 hours of exposure. In three subsequent experiments we could show a consistent and repeatable behavioural response pattern consisting of immediate avoidance reactions expressed as "shooting behaviour" following each $\mathrm{pH}$-reduction every hour. The animals responded in a rapid manner to the shifts at all $\mathrm{pH}$ values, suggesting that these animals are sensitive to even relatively small changes. The results indicate that repeated acute $\mathrm{pH}$-stress caused by $\mathrm{CO}_{2}$-leakage from carbon storage sites might affect the behaviour and subsequent fitness of natural populations of common shrimps. Changes in behaviour are likely to lead to increased predation on these animals and migration away from affected areas.
\end{abstract}

Keywords: Behaviour; Avoidance; Shrimp; $\mathrm{pH}$; $\mathrm{CO}_{2}$ Injection; CCS; Acidification

\section{Introduction}

Global carbon dioxide emissions linked to man's activeties amount to 30 billion tons per year, corresponding to 8.1 billion tons of carbon: 6.5 billion tons from burning fossil fuels and 1.6 billion tons from deforestation and agricultural practices. About half of it has been reabsorbed by vegetation and dissolved in the oceans, the latter causing acidification and potentially negative effects on marine life. The reminder has been accumulated in the atmosphere, where it causes climate change because carbon dioxide, a greenhouse gas, traps sun's heat on the earth [1].

During the last ice ages carbon dioxide naturally accumulated in the oceans with releases during warmer time periods, however studying ice cores from the Antarctica by isotopic carbon analysis it could be shown that during the last 800,000 years there has never been as much as carbon dioxide in the atmosphere as today [2].
Currently, each year the ocean absorbs approximately $25 \%$ of all carbon dioxide we emit, ocean acidification has increased by $30 \%$ since the beginning of the Industrial revolution, i.e. ca. 250 years ago, and the rate of acidification will accelerate in the coming decades, i.e. further projections estimate an increase of acidification by $120 \%$ until 2060 . As carbon dioxide dissolves better at lower temperatures, cold oceans are hit harder by ocean acidification than warmer seas. Increasing temperatures by climate change might counteract ocean acidification to a small extent [3].

CCS (Carbon Capture and Storage) business comprises capture of $\mathrm{CO}_{2}$ at emission sources, transport by pipelines and ship to storage locations and injection into a suitable host rock geological formation, such as depleted natural gas - and oil fields, saline aquifers and unminable coal fields. After injection carbon dioxide accumulates in the rock pores while displacing other gas, oil and 
water. Rocks with high porosity and permeability, such as in sedimentary basins, such as sandstone (on land and in the ocean) represent most appropriate geological formations for CCS [1].

Carbon dioxide is transported and compressed as dense fluid and injected on site under pressure. During injection the surrounding water gets acidified. Long-term storage of carbon dioxide might lead to upwards movement and migration into other rock formations. Dissolution of and chemical reaction with minerals might change bioavailability of minerals and metals [1].

Monitoring of these processes is needed: operational $\left(\mathrm{CO}_{2}\right.$ injection), safety and environmental (effects), society and financial. The EU Directive from 2008 on CCS demands monitoring. The following targets have to be monitored: plume imaging of the injection, cap-rock integrity $\left(\mathrm{CO}_{2}\right.$ migration), well integrity $\left(\mathrm{CO}_{2}\right.$ escape upwards to surface), migration to other rock layers [1].

Research is needed to study the effects of ocean acidification as an acute threat during carbon dioxide injection as well as chronic effects from long term or repeated lowdose releases and upwards migration of carbon dioxide on aquatic life. Apparently fish and shellfish larvae seem to be the most vulnerable taxa as well as corals [3]. Such scientific results will affect future monitoring requirements and schemes to protect sea-life.

Some laboratory studies already indicated severe effects of low $\mathrm{pH}$ ( $\mathrm{pH}$ between 7.0 and 6.0) on marine benthic fauna recorded as decrease in survival and reproduction in crustaceans and polychaetes [4], increased shell abnormalities and decreased shell thickness/size in Abalone [5] and M. edulis [6], disrupted immune defense, such as impaired phagocytosis of pathogenous bacteria in Mytilus edulis under chronic exposure to $\mathrm{pH} 6.5$ [7] and severe effects on blood $\mathrm{pH}$ and haemocyte functionality in M. edulis [8]. A two week exposure of the crab Necora puber to a $\mathrm{pH}$ range from $\mathrm{pH} 8.0$ down to 6.0 showed a compensatory dissolution of carbonates from the exoskeleton in order to maintain acid base balance in body fluids [9], in contrary to the findings of Small et al. [10], who reported no net shell dissolution during $30 \mathrm{~d}$ of exposure to $\mathrm{pH}$ down to $\mathrm{pH} 6.7$.

Hypercapnia $\left(\mathrm{pCO}_{2} \geq 1000 \mu \mathrm{atm}\right)$ had a narcotic effect causing lethargy in the sea star O. schayeri [11]. Narcotic effects of hypercapnia are well documented in insects and several invertebrates: whereas in some organisms hypercapnia induces an increase in the neurotransmitter adenosine, a nervous system depressor, in decapods, narcotic effect of hypercapnia appears to be due to accumulation of $\mathrm{Mg}^{+2}$ from dissolution of the exoskeleton to compensate for the acidosis [11].

Field biomonitoring studies showed changes in species composition at carbon dioxide dumping sites, such as de- creases in molluscs and gammaridea abundances below $\mathrm{pH} 7$ [12] and altered community function, such as affected nutrient cycling and bioturbation [13].

\section{Aim}

The aim of this investigation is to study potential acute behavioural responses to acidification by carbon dioxide injection in the common shrimp Crangon crangon under short term exposures to stepwise $\mathrm{pH}$-decreases. It is intended to provide threshold values of response for these animals to inform the debate on environmental risks and could lead to future development of a field monitoring system.

\section{Materials and Methods}

\subsection{Test Species}

Crangon crangon (Crustacea, Decapoda) is a geographically widely spread edible marine shrimp with high abundances in the North Sea, North Atlantic and Mediterranean Sea [14]. The shrimp Crangon crangon is a key species of the coastal areas of the North Sea. It appears in high numbers and represents a significant food source for fishes and it is also an important predator on many invertebrates [15].

C. crangon shows tail-flip escape responses when exposed to a natural predator, the cod Gadus morhua, or an artificial stimulus. Shrimps escaped by rolling to their left or right during the initial tail-flip of a response, and thereafter swam on their side [16]. Similar escape/avoidance responses may be expected to chemical stressors, which might be used in biomonitoring systems.

Both ecological and economic considerations are the basis for the concern about potential negative effects of ocean acidification on this species. C. crangon tolerates a wide range of temperatures, salinities $(17 \% 0-32 \%$ [14]; $29 \%$ - 31\%o [17]) and substrates [14], as it also survives in coastal and estuarine regions in the North Sea and migrates seasonally from shallow to deeper regions. In spring-tide periods the shrimps are exposed to tidal salinity fluctuations ranging from $35 \%$ to $25 \%$ in summer and from $34 \%$ to $14 \%$ in winter [18]. Populations in the North Sea exhibit a diurnal activity rhythm with peaks in the night. Although being predators they do not actively hunt, rather wait for appropriate prey to come close. The shrimps use olfaction to detect their prey. During the day they often burrow in the upper sediment layers, indicating a rather inactive and passive behaviour.

\subsection{Experimental Setup and Design}

The acute acidification experiments were performed in a flow-through system, with constant renewal of fresh seawater filtered through sand $\left(9^{\circ} \mathrm{C}, 34 \%\right)$, being distributed 
equally from a head tank to the 4 glass tanks $(6 \mathrm{~L}$, flow rate of $500 \mathrm{ml}$ per minute per tank). Carbon dioxide was fed into a header tank via a regulator and monitoring system that maintained $\mathrm{pH}$ at the desired level (Figure 1).

The shrimps were collected from a local beach using a push net then returned to the laboratory where they were acclimated to the local water conditions ( $\mathrm{pH}$ 8.1 PSU, $\left.9^{\circ} \mathrm{C}\right)$ for at least one day before use. Juvenile (2.0 - 3.5 $\mathrm{cm})$ specimens were selected randomly for the experiments. Three subsequent $\mathrm{pH}$-experiments as well as a control with four animals in each set were performed in reduced light conditions and during the same period of the day, following an identical scheme of stepwise $\mathrm{pH}$ decreases with hourly decreases by $0.2 \mathrm{pH}$ units between $\mathrm{pH} 7$ down to $\mathrm{pH} 6$.

Figure 1 shows $\mathrm{CO}_{2}$ lines going into both header tanks - in this experiment, it feeds into just one. In each tank one test chamber of the MFB is placed, with one animal in each test chamber.

Behaviour of the shrimps was recorded quantitatively and online with the Multispecies Freshwater Biomonitor (MFB) based on quadropole impedance conversion technique $[19,20]$. Shrimps $(2.0-3.5 \mathrm{~cm})$ were placed individually in cylindrical sensor chambers $(5 \mathrm{~cm}$ length, 2 $\mathrm{cm}$ inner diameter) capped with screw lids holding nylon nets $(0.2 \mathrm{~mm})$ on both ends to allow flow-through of seawater. Previous experiments with Corophium volutator $[21,22]$ as well as with Carcinus maenas [23] proved the MFB could function in brackish and fully marine waters.

\subsection{Statistical Analysis}

Statistical analysis was performed in SigmaPlot 12 using non-parametric statistics. Experiments with subsequent $\mathrm{pH}$ shifts $(0.2 \mathrm{pH}$ units) were analysed with repeated measures ANOVA on ranks to show differences between

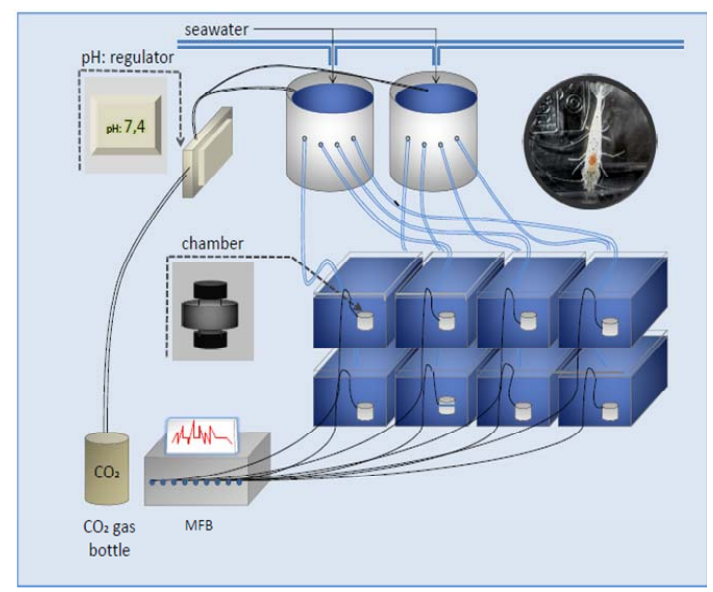

Figure 1. Experimental setup. individuals within one specific experiment and to show differences between the three subsequent experiments compared to the control at $\mathrm{pH}$ 8.05. Moreover, differrences in activity levels (\% activity increase directly after versus directly before each $\mathrm{pH}$ shifts) were tested with ANOVA on ranks. All graphs were produced in SigmaPlot 12.

\section{Results}

\subsection{Behavioural Pattern of $C$. crangon}

As benthic species both adult and juvenile C. crangon are mostly resting on/in the sediment during the daytime. They show an endogenous rhythm that controls the majority of their activities to the hours of darkness. Deviation away from this pattern will leave them susceptible to the many predators that hunt them by sight. In the MFB three different types of behaviour could be discerned: 1) sporadic rapid short distance swimming ("shooting behaveiour", Figure 2), i.e. single peaks of high amplitudes, 2) episodic undulation of the abdominal legs ("ventilation"), i.e. regular almost mono-frequent signals of low amplitudes $(1-2 \mathrm{~Hz})$ for time periods of ca. 5 - 10 seconds and c) resting or inactivity, i.e. no signal above the baseline.

\subsection{Responses of $C$. crangon to Stepwise pH Downshifts}

Stepwise pH-decreases between 7 and 6 PSU were applied to simulate possible leakage of $\mathrm{CO}_{2}$ from storage sites into seawater. Prior to the shifts the animals had been acclimated to the test chambers overnight. Stepwise $\mathrm{pH}$-decrease caused immediate increase of activity by the animals followed by a return to the normal resting behaviour afterwards. These "activity waves" show that the animals react fast and in a very sensitive manner to subsequent $\mathrm{pH}$-decreases of only 0.2 units per hour (Figures 3 and $\mathbf{4})$.

The observed activity pattern (Figure 3) was found identically in 3 subsequent experiments: directly after a $\mathrm{pH}$-decrease locomotion (shooting behaviour) increased significantly, i.e. the animals sensed the changes in acidity and reacted with increased activity, indicating avoidance. This response lasted for about 30 minutes, i.e. the animals calmed down before the next $\mathrm{pH}$-decrease.

The change in activity expressed as difference of activity after versus before the $\mathrm{pH}$ shift was plotted for all experiments pooled versus the $\mathrm{pH}$ intervals of $\mathrm{pH}$ shifts (Figure 5). It can be seen that the animals detect all $\mathrm{pH}$ shifts in a similar intensity of response, with no significant differences between a) the 3 experiments and b) $\mathrm{pH}$ steps (ANOVA on ranks). Whereas 10 of the 12 tested animals responded within $10 \mathrm{Min}$. of $\mathrm{pH}$ downshift, 2 


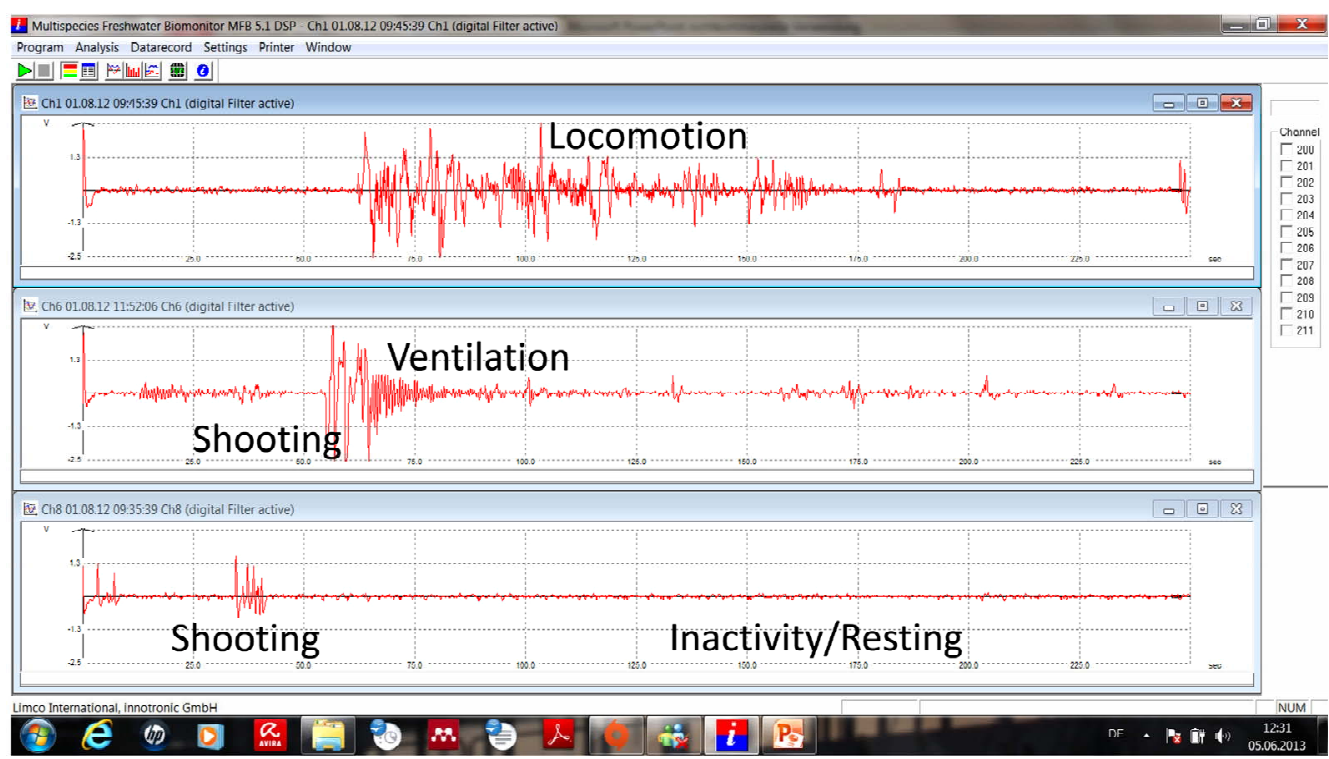

Figure 2. Different types of behaviour of $C$. crangon recorded by the MFB.

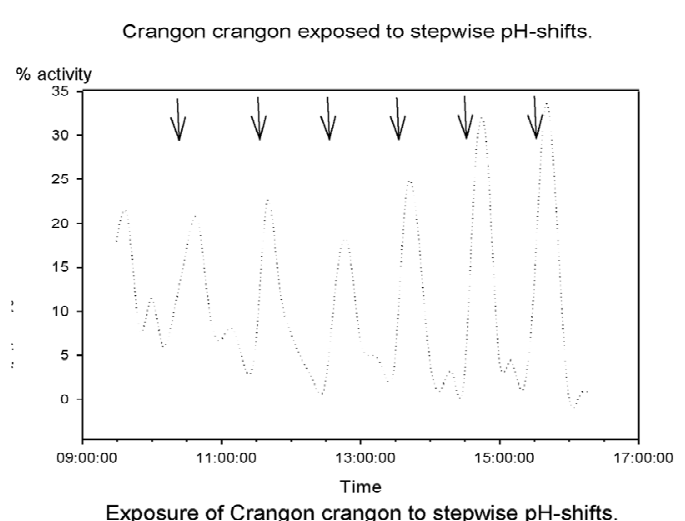

Crangon crangon exposed to stepwise $\mathrm{pH}$-shifts
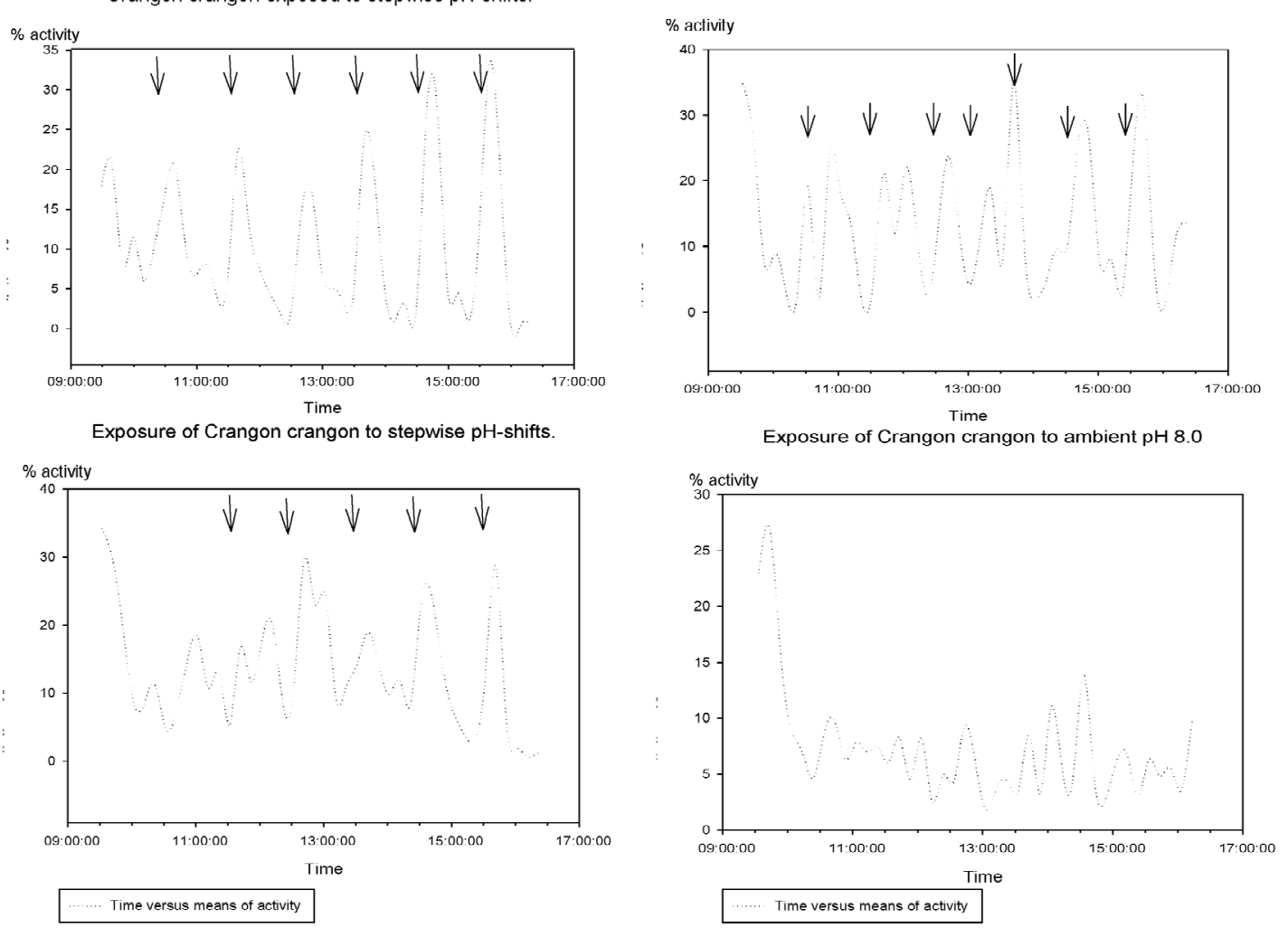

Figure 3. Overview over the activity of 4 C. crangon $(2.0-3.5 \mathrm{~cm})$ following the pH-decreases (pH 8 to $\mathrm{pH} 7.0$ and further down in 0.2 units (marked with arrows) Three subsequent experiments and the control are presented.

responded later, i.e. after 20 - 30 Min.

\section{Discussion}

The animals reacted rapidly and sensitively to small $\mathrm{pH}-$ decreases with increased avoidance (shooting behaviour) within 10 - 20 Min. after start of $\mathrm{pH}$-decrease. This pattern was constant and repeatable. The avoidance response might be comparable to the tail-flip behaviour, which has 


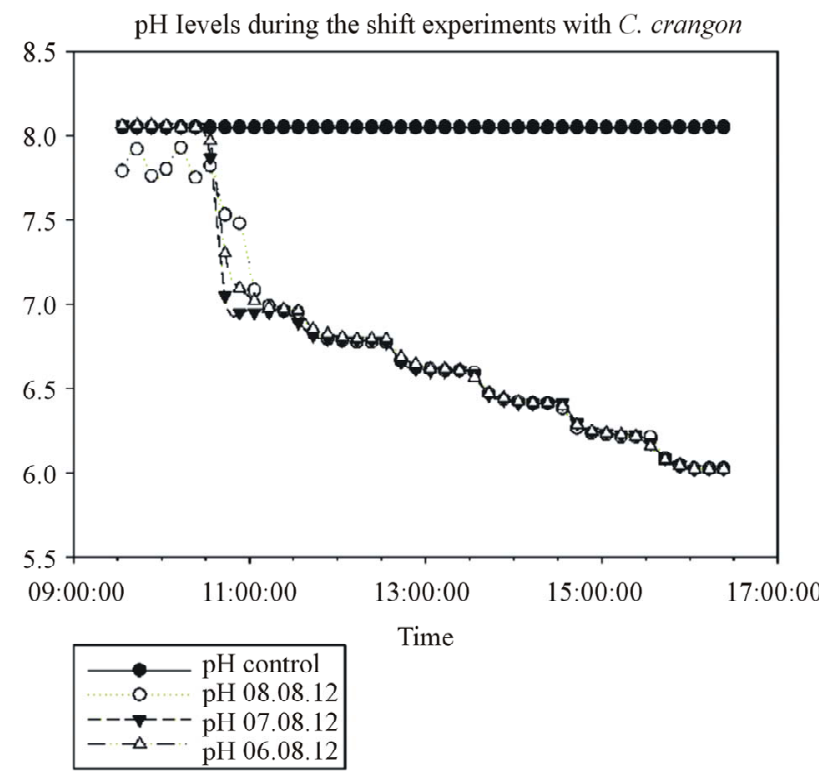

Figure 4. Stepwise pH-decrease (0.2 units) in 3 subsequent experiments compared to the control.

Increase in activity (Difference) of Crangon crangon before versus after $\mathrm{pH}$ downschift ( 0.2 units) from $\mathrm{pH} 7$ to 6

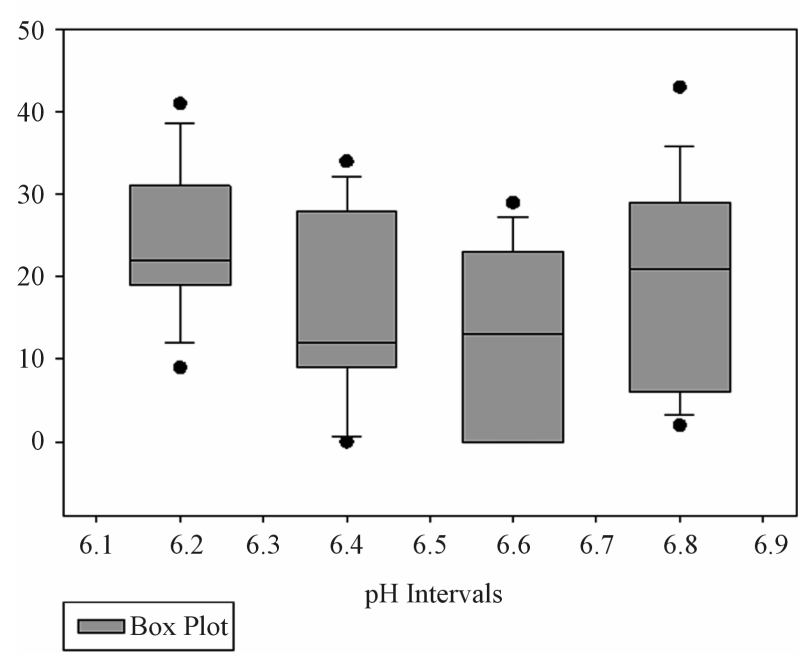

Figure 5. Degree of increase in avoidance (\% activity) in Crangon crangon directly after $\mathrm{pH}$ decrease.

been described as predator avoidance before [16]. The whole data-series exhibited a series of "waves" of increasing activity due to hourly $\mathrm{pH}$-downshifts, resembling a sinus function. Similar results have been reported earlier while studying the locomotory activity of Daphnia magna followed by repeated artificial light stimuli every 2 hours [24]. The observed sensitivity and rapidity of the responses of $C$. crangon indicate that $\mathrm{CO}_{2}$ leakage from carbon storage sites might have severe acute effects on shrimp behaviour. These effects might be reversible for some time as in our short term experiment, however repeated stress might weaken the fitness of the organisms in the long term. Moreover, avoidance responses expose the benthic shrimps to potential predators, as they leave their shelter. Lower fitness and increased predator vulnerability might lead to reduced population density. Also migration away from a region is possible.

The effects of CCS on the behaviour of marine invertebrates have barely been studied, therefore comparative literature is lacking. Most previous studies dealt with physiological changes due to $\mathrm{pH}$ decreases in marine mussels, some with crabs, however, behavioural studies are rare. The same applies to effects of acidfication in freshwater habitats (e.g. Herrmann et al. 1993).

Behavioural responses to $\mathrm{pH}$-decreases (from circumneutral $\mathrm{pH}$ down to $\mathrm{pH} 3.5$ ) during a period of $48 \mathrm{~h}$ were performed with Daphnia magna showing decreased locomotion and ventilation (pH 7 - 3.5), with a steep linear regression slope [25]. No avoidance response could be seen. This might be due to the difference in the behavioural response patterns of the planktonic daphnids compared to the benthic shrimps.

The decapod Atyaephyra desmaresti showed decreased activity under direct exposure to low pH-AMD (natural Acid Mine Drainage: acid $\mathrm{pH}$ combined with high metal ion levels) with the lowest observed response time (LORT) of $5 \mathrm{~h}$ at $\mathrm{pH} 5.0$ [26]. In exposures to acid water without metal ions, stress behaviour of $A$. desmaresti consisted of decreasing activity and loss of diel rhythmicity at $\mathrm{pH} 4.4$ within $48 \mathrm{~h}$ [27]. In these studies the freshwater shrimps did not have any time for a transient avoidance response, as they were exposed directly into very low $\mathrm{pH}$ causing directly irreversible toxic effects on behaviour and survival. Such a situation might happen in the sea in case of an accident during carbon injection procedure.

Freshwater crustaceans tolerate much lower $\mathrm{pH}$ levels than marine crustaceans, which might be due to differrences in ionregulation and osmoregulation. While freshwater organisms need to regulate their body to be highly hyperosmotic, marine organisms do have almost the same osmotic conditions in their body as in the surrounding sea water. Their regulation of the smaller differences might cause a more sensitive response to small $\mathrm{pH}$ changes. In freshwater habitats the critical $\mathrm{pH}$ for most invertebrates to maintain a viable population is around 5 - 5.5 [28], only some tolerant in-benthic insects or air-breathing insects can cope with lower pH-levels [26].

\section{Acknowledgements}

We kindly acknowledge the technical support by Sara Gerhardt and Stig Westerlund for constructing the $\mathrm{pH}-\mathrm{re}-$ gulation system. The project was funded by NFR CLIMIT Nr. 215637 (Dr. Shaw Bamber). 


\section{REFERENCES}

[1] R. Arts, "What Does $\mathrm{CO}_{2}$ Geological Storage Really Mean?" $\mathrm{CO}_{2}$ GeoNet European Network of Excellence, 2008, 19 p.

[2] J. Schmitt, R. Schneider, J. Elsig, D. Leuenberger, A. Lourantou, J. Chappellaz, P. Köhler, J. Fortunat, T. F. Stocker, M. Leuenberger and H. Fischer, "Carbon Isotope Constraints on the Deglacial $\mathrm{CO}_{2}$ Rise from Ice Cores," Science Express, Vol. 336, No. 6082, 2012, pp. 711-714. doi:10.1126/science.1217161

[3] Ocean Acificiation Reference User Group, "Ocean Acidification. The Facts. A Special Introductory Guide for Policy Advisers and Decision Makers," In: D. A. Laffoley and J. M. Baxter, Eds., EU Project on Ocean Acidification (EPOCA), 2009, 12 p.

[4] M. Cigliano, M. C. Gambi, R. Rodolfo-Metalpa, F. P. Patti and J. M. Hall-Spencer, "Effects of Ocean Acidification on Invertebrate Settlement at Volcanic $\mathrm{CO}_{2}$ Vents," Marine Biology, Vol. 157, No. 11, 2010, pp. 2489-2502. doi:10.1007/s00227-010-1513-6

[5] R. N. Crim, J. M. Sunday and C. D. G. Harley, "Elevated Seawater $\mathrm{CO}_{2}$ Concentrations Impair Larval Development and Reduce Larval Survival in Endangered Northern Abalone (Haliotis kamtschatkana)," Journal of Experimental Marine Biology and Ecology, Vol. 400, No. 1-2, 2011, pp. 272-277. doi:10.1016/j.jembe.2011.02.002

[6] J. Thomson and F. Melzner, "Moderate Seawater Acidification Does Not Elicit Long-Term Metabolic Depression in the Blue Mussel Mytilus edulis", Marine Biology, Vol. 157, No. 12, 2010, pp. 2667-2676. doi:10.1007/s00227-010-1527-0

[7] R. P. Ellis, H. Parry, J. I. Spicer, T. H. Hutchinson, R. K. Pipe and S. Widdicombe, "Immunological Function in Marine Invertebrates: Responses to Environmental Perturbation," Fish \& Shellfish Immunology, Vol. 30, No. 6, 2011, pp. 1209-1222. doi:10.1016/j.fsi.2011.03.017

[8] R. Bibby, S. Widdicombe, H. Parry, J. Spicer and R. Pippe, "Effects of Ocean Acidification on the Immune Response of the Blue Mussel Mytilus edulis," Aquatic Biology, Vol. 2, No. 1, 2008, pp. 67-74. doi:10.3354/ab00037

[9] J. L. Spicer, A. Raffo and S. Widdicombe, "Influence of $\mathrm{CO}_{2}$-Related Seawater Acidification on Extracellular Acid-Base Balance in the Velvet Swimming Crab Necora puber," Marine Biology, Vol. 151, No. 3, 2007, pp. 11171125. doi:10.1007/s00227-006-0551-6

[10] D. Small, P. Calosi, D. White, J. I. Spicer and S. Widdicombe, "Impact of Medium-Term Exposure to $\mathrm{CO}_{2}$ Enriched Seawater on the Physiological Functions of the Velvet Swimming Crab Necora puber," Aquatic Biology, Vol. 10, No. 1, 10, 2010, pp. 11-21. doi:10.3354/ab00266

[11] A. B. Christensen, H. D. Nguyen and M. Byrne, "Thermotolerance and the Effects of Hypercapnia on the Metabolic Rate of the Ophiuroid Ophionerein schayeri: Inferences for Survivorship in a Changing Ocean," Journal of Experimental Marine Biology and Ecology, Vol. 403, No. 1-2, 2011, pp. 31-38. doi:10.1016/j.jembe.2011.04.002
[12] R. Hale, P. Calosi, L. McNeill, N. Mieszkowska and S. Widdicombe, "Predicted Levels of Future Ocean Acidification and Temperature Rise Could Alter Community Structure and Biodiversity in Marine Benthic Communities," Oikos, Vol. 120, No. 5, 2011, pp. 661-674. doi:10.1111/j.1600-0706.2010.19469.x

[13] S. Widdicombe, S. L. Dashfield, C. L. McNeill, H. R. Needham, A. Beesley, A. McEvoy, S. Öxnevad, K. R. Clarke and J. A. Berge, "Effects of $\mathrm{CO}_{2}$ Induced Seawater Acidification on Infaunal Diversity and Sediment Nutrient Fluxes," Marine Ecology Progress Series, Vol. 379, 2009, pp. 59-75. doi:10.3354/meps07894

[14] A. Temming, C. Rückert and M. Hufnagel, "Entwicklung, Parametrisierung und Anwendung Eines Spezifischen Y/R Modells für die Nordseegarnele C. crangon L. zur Beurteilung des Befischungszustandes," Abschlussbericht Projektnr 03HS030, Institut für Hydrobiologie und Fischereiwissenschaften, Hamburg, 2008.

[15] R. Saborowski, U. Bickmeyer and C. Sahlmann, "Relation between $\mathrm{pH}$ and Enzyme Expression in the Midgut Gland of the Brown Shrimp Crangon crangon," Comparative Biochemistry and Physiology Part A: Molecular \& Integrative Physiology, Vol. 151, No. 1, 2008, 16 p.

[16] S. A. Arnott, D. M. Neil and A. D. Ansell, "Escape Trajectories of the Brown Shrimp Crangon crangon and a Theoretical Consideration of Initial Escape Angles from Predators," Journal of Experimental Biology, Vol. 202, No. 2, 1999, pp. 193-209.

[17] P. A. Haefner Jr., "The Effect of Low Dissolved Oxygen Concentrations on Temperature/Salinity Tolerance of the Sand Shrimp, Crangon septemspinosa Say," Physiological Zoology, Vol. 43, No. 1, 1970, pp. 30-37.

[18] M. Regnault, "Salinity-Induced Changes in Ammonia Excretion Rate of the Shrimp C. crangon over a Winter Tidal Cycle," Marine Ecology Progress Series, Vol. 20, 1984, pp. 119-125. doi:10.3354/meps020119

[19] A. Gerhardt, M. Clostermann, B. Fridlund and E. Svensson, "Monitoring of Behavioral Patterns of Aquatic Organisms with an Impedance Conversion Technique," Environment International, Vol. 20, No. 2, 1994, pp. 209219.

[20] A. Gerhardt, A. Carlssson, C. Ressemann and K. P. Stich, "A New Online Biomonitoring System for Gammarus pulex (L) (Crustacea: In Situ Test below a Copper Effluent in South Sweden," Environmental Science \& Technology, Vol. 31, No. 1, 1998, pp. 150-156. doi:10.1021/es970442j

[21] A. J. Kirkpatrick, A. Gerhardt, J. T. A. Dick, M. McKenna and J. A. Berges, "Use of the Multispecies Freshwater Biomonitor to Assess Behavioural Changes of Corophium volutator (Pallas, 1766) (Crustacea, Amphipoda) in Response to Toxicant Exposure in Sediment," Ecotoxicology and Environmental Safety, Vol. 64, No. 4, 2005, pp. 298-303.

[22] C. Kienle and A. Gerhardt, "Behavior of Corophium volutator (Crustacea, Amphipoda) Exposed to the WaterAccomodated Fraction of Oil in Water and Sediment," Environmental Toxicology and Chemistry, Vol. 27, No. 3, 2008, pp. 599-604. doi:10.1897/07-182.1 
[23] S. C. Stewart, J. T. A. Dick, P. R. Laming and A. Gerhardt, "Assessment of the Multispecies Freshwater Biomonitor (MFB) in a Marine Context: The Green Crab (Carcinus maenas) as Early Warning Indicator," Journal of Environmental Monitoring, Vol. 12, No. 8, 2010, pp. 1566-1574. doi:10.1039/b925474a

[24] A. Gerhardt, L. J. de Bisthoven and S. Schmidt, "Automated Recording of Vertical Negative Phototactic Behaviour in Daphnia magna (Crustacea)," Hydrobiologica, Vol. 559, No. 1, 2006, pp. 433-441. doi:10.1007/s10750-005-1259-1

[25] A. Gerhardt, L. J. de Bisthoven and E. Penders, "Quality Control of Drinking Water from the River Rhine (Netherlands) with the Multispecies Freshwater Biomonitor," Aquatic Ecosystem Health Management Society, Vol. 6, No. 2, 2003, pp. 159-166.
[26] A. Gerhardt, L. J. de Bisthoven and A. M. V. M. Soares, "Macroinvertebrate Response to Acid Mine Drainage: Community Metrics and On-Line Behavioural Toxicity Bioassay," Environmental Pollution, Vol. 130, No. 2, 2004, pp. 263-274. doi:10.1016/j.envpol.2003.11.016

[27] L. Janssens de Bisthoven, A. Gerhardt, K. Guhr and A. M. V. M. Soares, "Behavioral Changes and Acute Toxicity to the Freshwater Shrimp Atyaephyra desmaresti Millet (Decapoda: Natantia) from Exposure to Acid Mine Drainage," Ecotoxicology, Vol. 15, No. 2, 2006, pp. 215-227. doi:10.1007/s10646-005-0052-2

[28] A. Gerhardt, "Impact of Heavy Metals on Stream Invertebrates with Special Emphasis on Acid Conditions," Water, Air and Soil Pollution, Vol. 66, No. 3-4, 1993, pp. 289-314. 